\title{
Correction to: Servant Leadership and Goal Attainment Through Meaningful Life and Vitality: A Diary Study
}

\author{
Raquel Rodríguez-Carvajal ${ }^{1}$ - Marta Herrero ${ }^{1}$ - Dirk van Dierendonck ${ }^{2}$. \\ Sara de Rivas ${ }^{3} \cdot$ Bernardo Moreno-Jiménez $^{1}$
}

Published online: 23 July 2021

(c) Springer Nature B.V. 2021

\section{Correction to: J Happiness Stud (2019) 20:499-521 https://doi.org/10.1007/s10902-017-9954-y}

In the original publication, the affiliation and e-mail of Sara de Rivas has been published incorrectly. The correct version is updated in this correction.

Publisher's Note Springer Nature remains neutral with regard to jurisdictional claims in published maps and institutional affiliations.

The original article can be found online at https://doi.org/10.1007/s10902-017-9954-y.

Raquel Rodríguez-Carvajal

raquel.rodriguez@uam.es

Marta Herrero

marta.herrerol@uam.es

Dirk van Dierendonck

dvandierendonck@rsm.nl

Sara de Rivas

sara.derivas@urjc.es

Bernardo Moreno-Jiménez

bernardo.moreno@uam.es

1 Departamento de Psicología Biológica y de la Salud, Facultad de Psicología, Universidad Autónoma de Madrid, Ciudad Universitaria de Cantoblanco, C/Iván P. Pavlov, 6, 28049 Madrid, Spain

2 Rotterdam School of Management, Erasmus University, Postbus 1738, 3000 DR Rotterdam, The Netherlands

3 Facultad de Ciencias de la Salud, Universidad Rey Juan Carlos, Avenida de Atenas, s/n, 28922 Alcorcón, Madrid, Spain 